\title{
CD44 enhances the epithelial-mesenchymal transition in association with colon cancer invasion
}

\author{
SANG HYUK CHO ${ }^{1}$, YEON SUN PARK ${ }^{1}$, HUN JIN KIM ${ }^{1}$, CHANG HYUN KIM ${ }^{1}$, \\ SANG WOO LIM ${ }^{1}$, JUNG WOOK HUH ${ }^{1}$, JAE HYUK LEE ${ }^{2}$ and HYEONG ROK KIM ${ }^{1}$ \\ Departments of ${ }^{1}$ Surgery and ${ }^{2}$ Pathology, Chonnam National University Hospital \\ and Medical School, Gwangju, Republic of Korea
}

Received February 11, 2012; Accepted April 19, 2012

DOI: $10.3892 /$ ijo.2012.1453

\begin{abstract}
The metastatic process involves the migration and invasion of cancer cells throughout the body to produce secondary tumors at distant sites. Through of epithelial-mesenchymal transition (EMT), cancer cells employ developmental processes to gain migratory and invasive properties. CD44 is the transmembrane adhesion receptor for Hyaluronan (HA) and plays a central role in the remodeling and degradation of HA that leads to cell migration, as well as to cancer invasion and metastasis. CD44 is highly expressed in primary and metastatic colon cancer but lowly expressed in normal tissues. We evaluated the impact of CD44 on EMT and invasion of colon cancer cells. The functional role of CD44 in EMT was determined by the overexpression or knockdown of CD44. CD44 was overexpressed by transfection with plasmid-RTPCR product and knockdown of CD44 by small hairpin RNA (shRNA)-mediated depletion of CD44 in SW480 colon cancer cells. Morphological changes were evaluated by confocal laser microscopy in the culture media. The expression of EMT markers (E-cadherin/N-cadherin/vimentin/fibronectin/actin/ MMPs) and CD44/EGFR/PI3K-Akt signaling were evaluated using western blotting. The influence of EMT in tumor biology was assessed with proliferation, migration and invasion assays. EMT changes increased in CD44-overexpressing SW480 cells and decreased in CD44 knockdown cells. CD44 activation induced expression of EGFR and activation of phosphatidylinositol 3' kinase (PI3K)/Akt and expression of glycogen synthase kinase-3 $\beta$ (GSK-3 $\beta$ ). In terms of EMT markers, CD44 downregulated E-cadherin expression, upregulated $\mathrm{N}$-cadherin, $\alpha$-actin, vimentin, fibronectin and MT1-MMP, and inhibited the formation of the membrane-associated E-cadherin- $\beta$-catenin complex, which resulted in cell invasion and migration.
\end{abstract}

Correspondence to: Professor Hyeong Rok Kim, Department of Surgery, Chonnam National University Hospital and Medical School, 8 Hakdong Dongku, Gwangju 501-757, Republic of Korea E-mail:drkhr@jnu.ac.kr

Key words: CD44, epithelial-mesenchymal transition, colon cancer, invasion

\section{Introduction}

Epithelial-mesenchymal transition (EMT), a highly conserved process governing morphogenesis, which occurs during a critical phase of embryonic development in multicellular organisms. In mammals, EMT first occurs at the blastula stage, during formation of the parietal endoderm, which later contributes to the extra embryonic tissues $(1,2)$. EMT is reactivated in a variety of diseases, including renal fibrosis, liver cirrhosis, breast cancer, and anterior polar cataracts. EMT comprises a shift in cell phenotype that plays an important role in morphogenetic events spanning embryogenesis important to heart valve formation, as well as in homeostatic mechanisms governing tissue regeneration, inflammation and wound healing. EMT also contributes to disease states, such as fibrosis and cancer. In the latter condition, EMT is thought to contribute to treatment resistance via its antiapoptotic effects (3). In epithelial cancer, EMT is characterized by a switch in cell membrane cadherins (from E- to N-cadherin), a change from apical-basal to frontback polarity, and acquisition of motility enabled in part by the restructuring of the actin cytoskeleton $(4,5)$. During EMT, epithelial cells lose cell polarity by downregulating the expression of cytokeratins and cell-cell adhesion molecules such as E-cadherin (6,7). The decrease in epithelial gene expression is accompanied by an increased expression of mesenchymal genes, including vimentin and fibronectin. Following passage through EMT, epithelial cells also acquire mesenchymal morphology in adherent culture, as well as increased motility and invasiveness $(8,9)$.

CD44 is the principal transmembrane adhesion receptor for hyaluronan (HA) and plays a central role in the remodeling and degradation of HA that leads to cell migration, as well as to cancer invasion and metastasis (10-13). The cytoplasmic tail of CD44 recruits ezrin-radixin-moesin (ERM) proteins that are linked to the actin cytoskeleton and thereby promote cell motility. Expression of CD44 is upregulated not only in cancer cells but also in cells associated with inflammatory diseases, and inflammation-mediated fibrosis in the lung and kidney. As a principal receptor for HA, CD44 participates in the activation of leukocytes and parenchymal cells in areas of inflammation, suggesting a role for CD44 in tissue remodeling and fibrosis $(14,15)$. Interactions between CD44 and cytoskeletal components suggest a potential to influence the adhesion 
and motility of fibroblasts, thereby supporting a role for CD44 in tissue remodeling (16-19). In vitro wound assays to compare the migratory properties of primary lung fibroblasts isolated from CD44 wild-type and CD44 deficient mice revealed that CD44 is important both in maintaining the integrity of the actin cytoskeleton and in facilitating an organized, directional migratory response to injury (20-23). CD44 also promotes MMP-dependent activation of EGFR, and exogenous EGFR rescues the morphological phenotype and velocity of migration of fibroblasts (24). CD44 may be critical for the migration of fibroblasts to sites of injury and the local effects of EGFR may depend on the activity of CD44 to control inflammation and initiate the repair process (25-27).

Metastasis is a complex process involving the spread of malignant tumor cells from a primary tumor site to a secondary organ and colonization of the distant organ. The progression of cancer has been shown to correlate directly with gene changes that regulate a number of steps responsible for metastasis, including EMT (28-31). In the process of EMT, cancer cells employ developmental processes to gain migratory and invasive properties. Here we have developed an in vitro model of EMT-associated invasion of colon carcinoma cells and clarified the HA-CD44 interaction. Finally, we aimed to evaluate the impact of CD44 on EMT and invasion of colon cancer cells.

\section{Materials and methods}

Cell culture. SW480 cells were obtained from the ATCC cell line bank. They were cultured in DMEM (Lonza) containing $1 \%$ penicillin and streptomycin, and $10 \%$ heat-inactivated fetal bovine serum. In all experiments, cells were maintained at $37^{\circ} \mathrm{C}$ in a humidified $5 \% \mathrm{CO}_{2}$ incubator.

Cell transfection. pcDNA6 vector (Invitrogen, San Diego, CA, USA) containing a GFP sequence and plasmid RT-PCR product (sense: AAGCTTCTCCGGACACCATGGAC, antisense: GTACCATGGTGTAGGTGTTACAC) was used for overexpression of CD44. Short hairpin RNA CD44 (sense: GACAGAAAGCCAAGTGGACTCAACGGAGA: OriGene Technologies, Inc., Rockville, MD, USA) and pGFP-V-RSvector containing a non-effective shRNA cassette against GFP were used for knockdown of CD44 expression. For transfection, approximately $2.0 \times 10^{4} \mathrm{SW} 480$ cells were seeded in 6-well plates. When the cells reached $60 \%-80 \%$ confluence, cells were transfected with pcDNA6, pGFP-V-RS shRNA-CD44 and pGFP-V-RS-NC (normal control) by use of Lipofectamine 2000 (Invitrogen), according to the manufacturer's instructions and the ratio of the plasmids to the transfection reagent was $1 \mu \mathrm{g}: 3 \mu \mathrm{l}$. At $48 \mathrm{~h}$ post-transfection, $500 \mu \mathrm{g} / \mathrm{ml}$ of puromycin (Sigma, St. Louis, MO, USA) was added to select stable transfected cell lines and individual clones were isolated. The stably-transfected cells were named as follows: SW480CD44-overexpression (transfected with pcDNA6 vector containing a CD44 plasmid), SW480-S-CD44 (transfected with pGFP-V-RS shRNA-CD44) and SW620-NC (transfected with pGFP-V-RS-vector containing a non-effective shRNA cassette).

Immunofluorescence microscopy. Indirect immunofluorescence microscopy using confocal laser was used for taking pictures of individual cells. In brief, cells on glass coverslips were fixed with $4 \%$ paraformaldehyde in phosphate buffered saline (PBS) and permeabilized with $0.1 \%$ Triton X-100 and $0.1 \%$ Tween-20 (Sigma). Samples were then incubated with primary antibodies for CD44 (Santa Cruz Biotechnology Inc., Santa Cruz, CA, USA), $\beta$-catenin (Santa Cruz Biotechnology Inc.), fibronectin (BD Biosciences, Oxford, UK), vimentin (Santa Cruz Biotechnology Inc.), MT1-MMP (Santa Cruz Biotechnology Inc.), E-cadherin (Cell Signaling, Danvers, MA, USA), N-cadherin (Cell Signaling) in PBS with $1 \%$ bovine serum albumin (BSA) for $1 \mathrm{~h}$. Negative control cells were incubated with $1 \% \mathrm{BSA}$ in parallel. Incubation with Alexa 594 and DAPI conjugated secondary antibody followed. Samples were mounted with Vectashield (Vector Laboratories, Burlingame, CA, USA) and examined with a Zeiss LSM 410 confocal laser-scanning immunofluoresence microscope (Olympus, Japan). Cells cultured on glass coverslips were fixed with $4 \%$ paraformaldehyde in PBS, the cells on glass were stained with Diff-Quick solution (Sysmex, Kobe, Japan) and checked for morphologic changes in 5 selected fields under a light microscope.

Cell viability and apoptotic assays. SW480 colon cancer and transfected cell lines were cultured in 96-well plates for $24 \mathrm{~h}$. Trypan blue dye exclusion or MTT assay for cell viability and apoptotic assay using Annexin V-APC were performed on the cell lines.

Reverse transcription-polymerase chain reaction. Total RNA was extracted from cultured cells using Trizol reagent (Invitrogen). RNA $(1 \mu \mathrm{g} / \mu \mathrm{l})$ was used to synthesize cDNA using Superscript First-Strand Synthesis Kit (Promega, Madison, WI, USA) following the manufacturer's protocols. Expression of CD44 mRNA was detected with RT-PCR (Takara, Shiga, Japan) using specific primers (CD44 primer sense and antisense; Table I).

Cell migration assay. Cells were cultured in a 6-well plate and transfected with CD44-plasmid. After incubation for $48 \mathrm{~h}$, a scratch wound was made by creating a linear cell-free region using a $200 \mu \mathrm{l}$ pipette tip resulting in a uniform gap. The medium was changed to 5\% FBS/DMEM media. The progress of cell migration into the scratch was photographed at 0,24 , and $48 \mathrm{~h}$ using an inverted microscope. The distance between gaps was normalized to $1 \mathrm{~cm}$ after capture of 6 random sites.

Cell invasion assay. Transwell filters (8.0 $\mu \mathrm{m}$ pores) were coated with matrigel/DMEM overnight and dried out at room temperature. Cells transfected with CD44-plasmid were seeded at $2 \times 10^{5}$ cells in $120 \mu 10.2 \%$ BSA medium in the upper chamber. Subsequently, $400 \mu 10.2 \%$ BSA medium containing $20 \mu \mathrm{g} / \mathrm{ml}$ human plasma fibronectin (Calbiochem, La Jolla, CA, USA), a chemotacic factor, were loaded into the lower chamber. After incubation for $24 \mathrm{~h}$, invaded cells on the bottom surface of the transwell were stained with Diff-Quick solution (Sysmex, Kobe, Japan) and counted in 5 selected fields under a light microscope. Data were expressed as the mean standard error (SE) of the number of cells/field in 3 individual experiments. 
Table I. Primers for RT-PCR.

\begin{tabular}{|c|c|c|}
\hline Protein & Primers & Sequences \\
\hline CD44 & $\begin{array}{l}\text { Forward } \\
\text { Reverse }\end{array}$ & $\begin{array}{l}\text { 5'-GAA TAT AAC CTG CCG CTT TG-3' } \\
\text { 5'-CTG AAG TGC TGC TCC TTT CAC-3' }\end{array}$ \\
\hline GAPDH & $\begin{array}{l}\text { Forward } \\
\text { Reverse }\end{array}$ & $\begin{array}{l}\text { 5'-ACC ACA GTC CAT GCC ATC AC-3' } \\
5^{\prime}-\mathrm{TCC} \text { ACC ACC CTG TTG CTG TA-3' }\end{array}$ \\
\hline
\end{tabular}

A

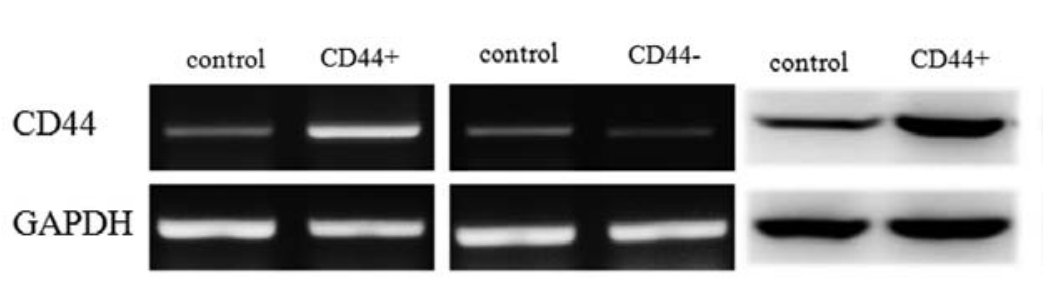

B

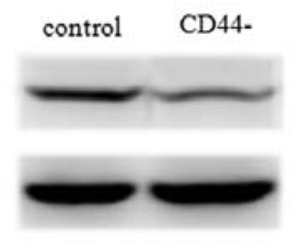

Figure 1. CD44 expression in stable transfectants detected by (A) RT-PCR and (B) western blotting, with GAPDH as the internal control. CD44+, overexpression of CD44; CD44-, knockdown of CD44.

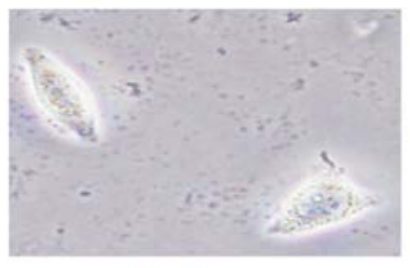

pcDNA6 vector

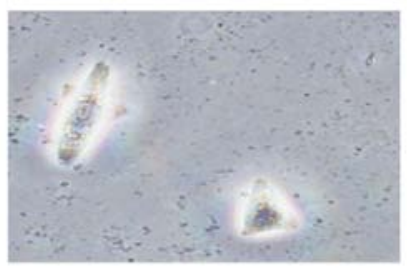

pGFP-V-RS vector

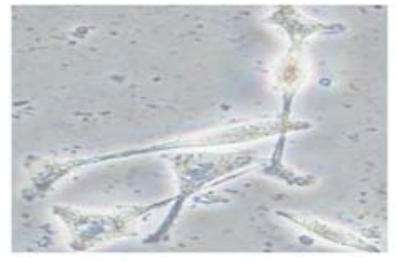

CD44 overexpression

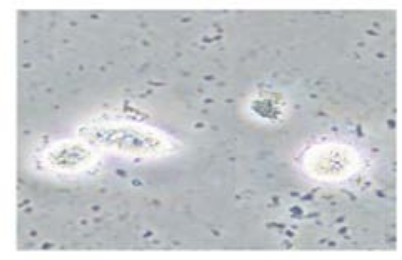

CD44 knockdown
Figure 2. Morphology of the SW480 cells expressing the empty vectors of CD44 plasmid or shRNA CD44 and CD44 overexpression or knockdown by phase contrast microscopy (x400).

Western blotting. The cells were washed twice with cold PBS and lysed with RIPA buffer (1 M Tris- $\mathrm{HCl}, 150 \mathrm{mM} \mathrm{NaCl}$, $1 \%$ Triton X-100, 2 mM EDTA) with $1 \mathrm{mM}$ PMSF, Halt phosphatase inhibitor, and Halt protease inhibitor cocktail (Thermo, Rockford, IL, USA) for $15 \mathrm{~min}$ on ice. The resolved proteins underwent centrifugation at $15,000 \mathrm{~g}$ for $20 \mathrm{~min}$ at $4^{\circ} \mathrm{C}$. The protein quantification of supernatants was determined using BCA protein assay (Thermo) and all samples were separated by $12 \%$ sodium dodecyl sulfate polyacrylamide gel electrophoresis (SDS-PAGE) and the separated proteins were transferred electrophoretically from the gel to the surface of PVDF membrane (Millipore, Billerica, MA, USA). The analysis used primary antibodies as described by the manufacturers of the antibodies; monoclonal anti-CD44
(Santa Cruz Biotechnology Inc.), EGFR (Cell Signaling), PDK1 (Cell Signaling), PI3k (Cell Signaling), p-AKT (Cell Signaling), GSK3 $\beta$ (Cell Signaling), GAPDH (Santa Cruz Biotechnology Inc.), $\beta$-catenin (BD Biosciences), E-cadherin (Cell Signaling), N-cadherin (Cell Signaling), Vimentin (Santa Cruz Biotechnology Inc.), Fibronectin (BD Biosciences), $\alpha$-actin (Santa Cruz Biotechnology Inc.), Garma-tuburin (Santa Cruz Biotechnology Inc.), MT1-MMP (Santa Cruz Biotechnology Inc.). After the final rinsing with TBST, the membrane was incubated with secondary HRP-linked anti-rabbit IgG or anti-mouse IgG for $1 \mathrm{~h}$. After washing, the immunoblots were visualized using chemiluminescence (ECL) HRP substrate (Millipore) and analyzed with an image analyzer (Ras-4000, Fujifilm, Tokyo, Japan)

\section{Results}

CD44 expression. CD44 expression was evaluated by RT-PCR and western blotting considering overexpression by plasmid RT-PCR product of CD44 and knockdown by shRNA CD44. As shown in Fig. 1, CD44 overexpressed cells showed increased expression of CD44 and CD44 knockdown cells showed decreased expression of CD44 compared to parental cells.

Morphologic changes. The round epithelial feature changed into a long tubular shape, which was characteristic of mesenchymal features in the CD44 overexpressed cells (Fig. 2). This is defined as epithelial mesenchymal transition (EMT). This phenomenon is prominent in CD44 overexpressed cells but no evidence of morphologic changes in parental and CD44 knockdown SW480 cells is seen.

Cell migration assay. As determined by the wound healing assay, CD44 overexpressed cells showed significantly increased cell migration compared to SW480 vector by $156 \%$ at Day 2. By contrast, CD44 knockdown cells showed a 
$\mathbf{A}$
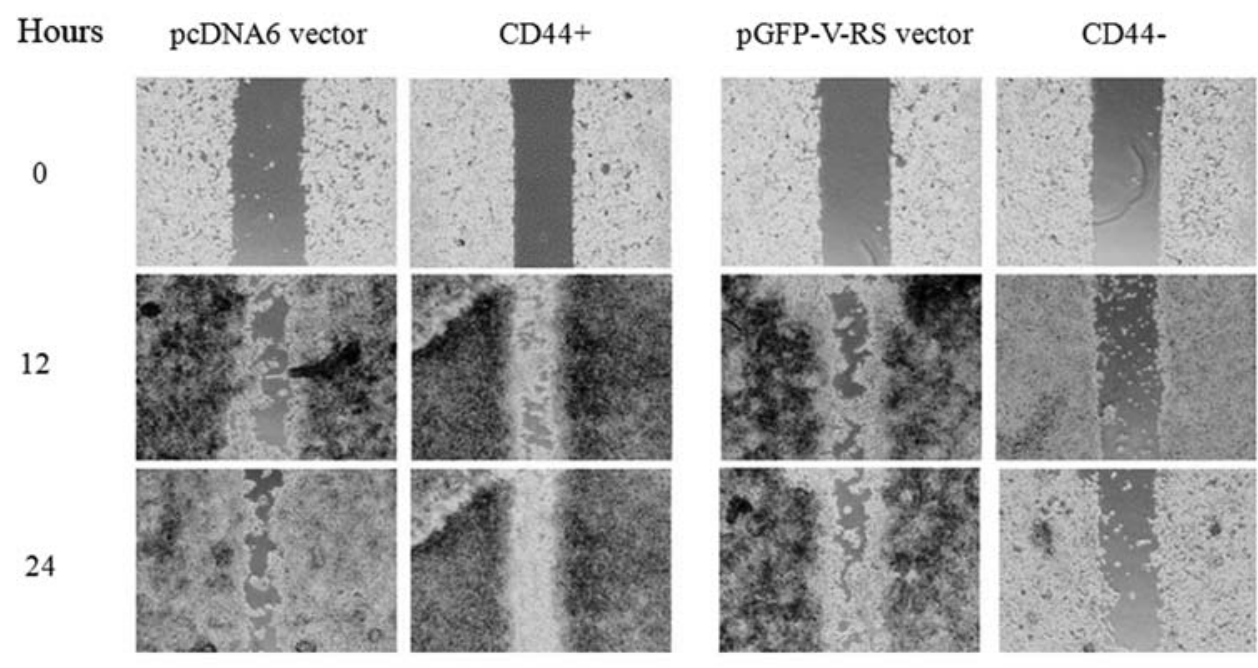

$\mathbf{B}$
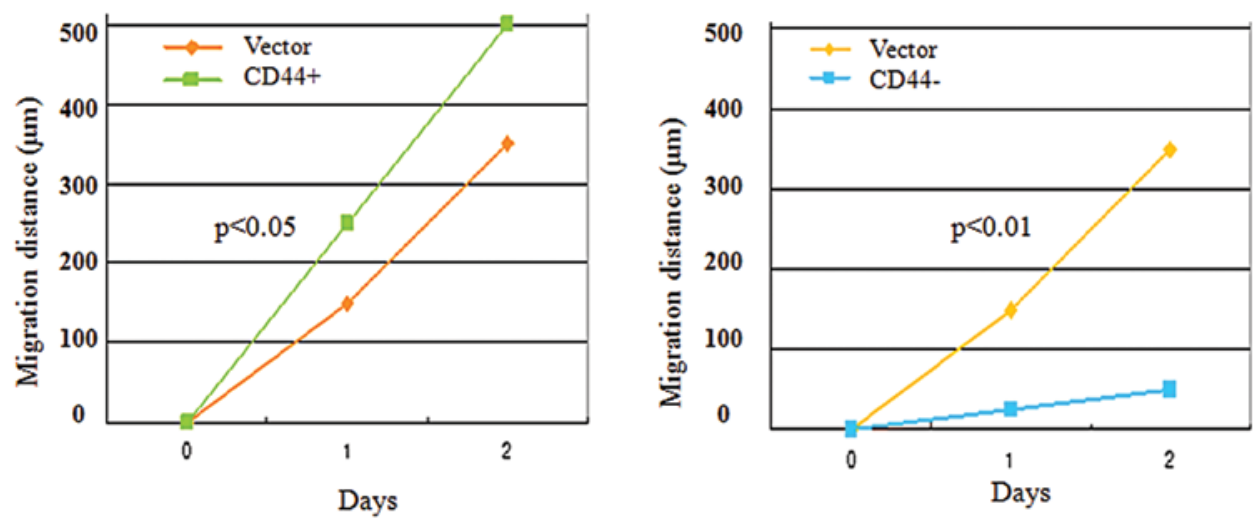

Figure 3. Migration capacity with the wound healing assay showed increased motion in CD44 overexpressed cells. (A) Optical microscopic images of in vitro wound healing at 0,24 and $48 \mathrm{~h}$ after the creation of wound. (B) Migration distances were measured at each time point $(\mu \mathrm{m})$. Data are the means \pm SD. CD44+, overexpression of CD44; CD44-, knockdown of CD44.

marked decreased migratory capacity compared to vector by $17 \%$ at Day 2 (Fig. 3).

Cell invasion assay. As determined by Matrigel invasion assay throughout transwell, CD44 overexpressed cells showed increased cell invasion compared to vector by $252 \%$, whereas shRNA CD44 decreased cell invasion by $71.05 \%$ in $24 \mathrm{~h}$ after cell plating (Fig. 4)

$\beta$-catenin expression. CD44 overexpressed cells showed upregulated $\beta$-catenin expression in the nucleus and a marked decrease of $\beta$-catenin in CD44 knockdown cells by western blot analysis and immunofluorescence microscopy using Alexa Fluor 594 and DAPI (Fig. 5).

Activation of AKT pathways. As a mediator of EMT inducer, CD44 triggered the EGFR-Akt signaling pathway, CD44 increased EGFR expression and expression of downstream molecules of EGFR: PI3K, AKT, GSK3 $\beta$. Western blot analysis showed increased expression of EGFR, PI3K, AKT, GSK3 $\beta$ in CD44 overexpressed cells and decreased expression in CD44 knockdown cells (Fig. 6).

EMT markers. To evaluate the direct correlation between CD44 and EMT, we examined the expressions of E-cadherin,
$\mathrm{N}$-cadherin, vimentin, fibronectin, $\alpha$-actin, MT1-MMP. CD44 overexpression of colon cancer cells inhibited E-cadherin expression, whereas it induced the expression of $\mathrm{N}$-cadherin, vimentin, fibronectin, $\alpha$-actin, MT1-MMP. By contrast, knockdown of CD44 increased E-cadherin expression and downregulated $\mathrm{N}$-cadherin, vimentin, fibronectin, $\alpha$-actin, and MT1-MMP in the western blotting (Fig. 7) and confocal immunofluorescence images (Fig. 8).

\section{Discussion}

The hallmarks of malignant transformation are the capabilities of invasion and metastasis. In order for these processes to proceed, tumor cells must be able to detach from the primary tumor, migrate, gain access to blood or lymphatic vessels and disseminate in the body (32). It is assumed that a dedifferentiation of the tumor cells in the invasive area characterized by a loss of an epithelial layer and the gain of a mesenchyme-like phenotype enables invasive and metastatic growth of differentiated colorectal cancers. This process is known as an epithelial-mesenchymal transition (EMT). EMT is very significant for malignant colorectal cancer progression (33). Several pathways involved in the developmental control of EMT are taken over during tumor formation by activation of oncogenic signaling and disruption of tumor suppressor networks. In this 

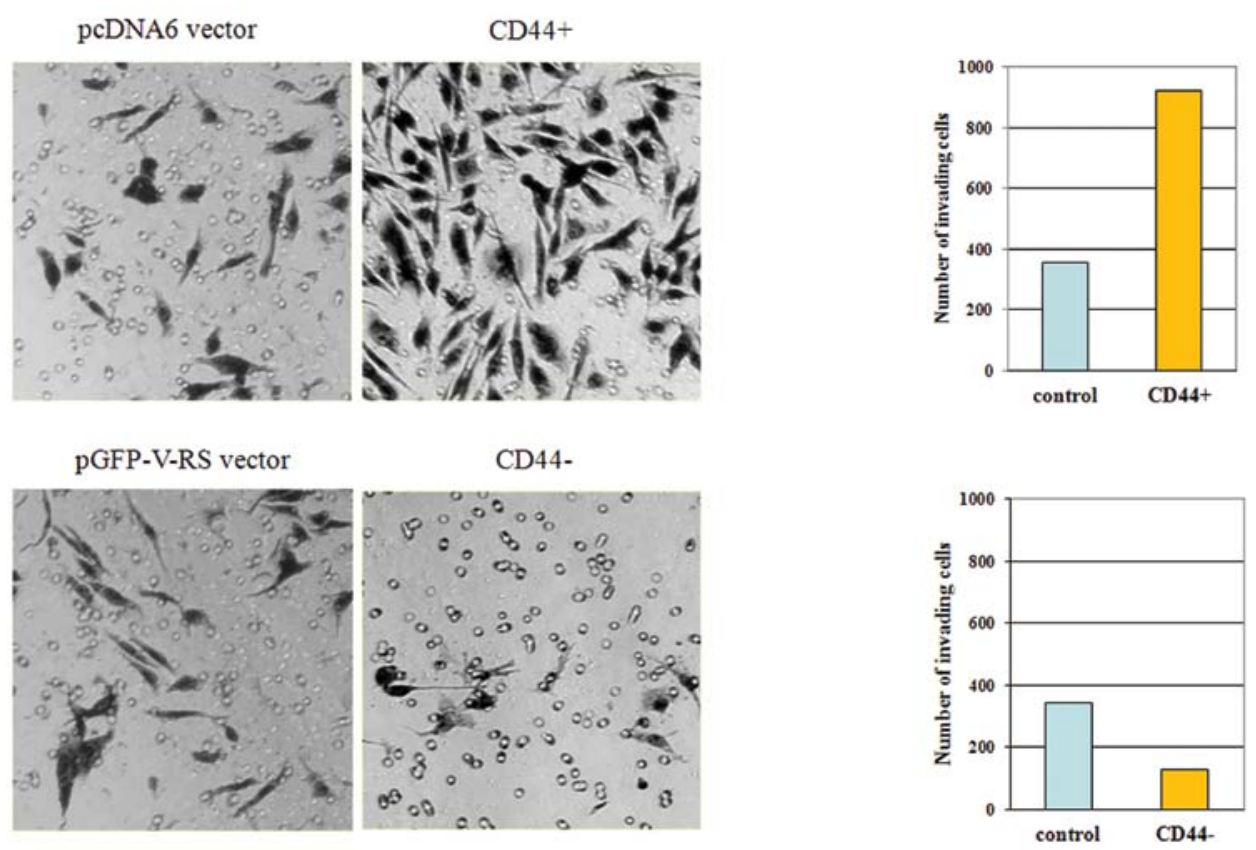

Figure 4. Matrigel invasion assay of single-cell clones derived from SW480 and CD44 transfected cell lines. Cells invading matrigel were stained with crystal violet on the underside of the chamber. CD44+, overexpression of CD44; CD44-, knockdown of CD44.

A

Vector CD44+ Vector CD44-

$\beta$-catenin

Nucleus matrix protein $\mathrm{p} 84$

B
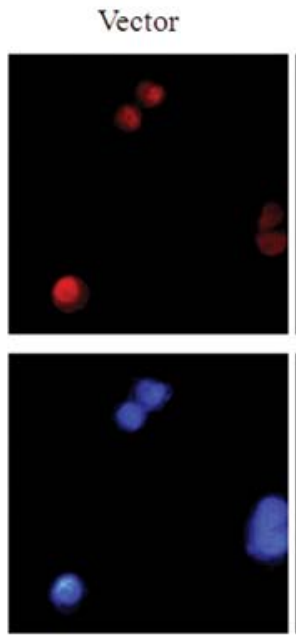

$\mathrm{CD} 44^{+}$
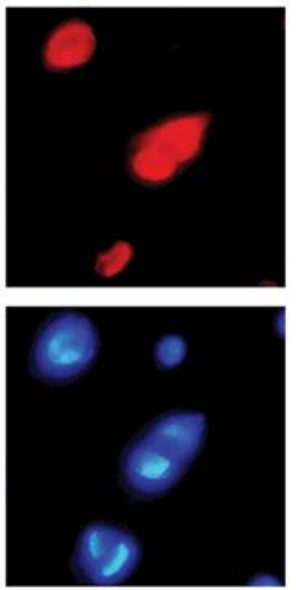

Vector
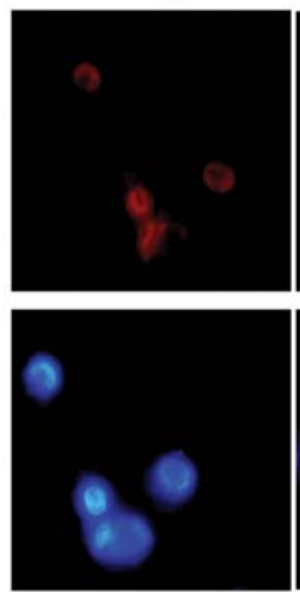

CD44-
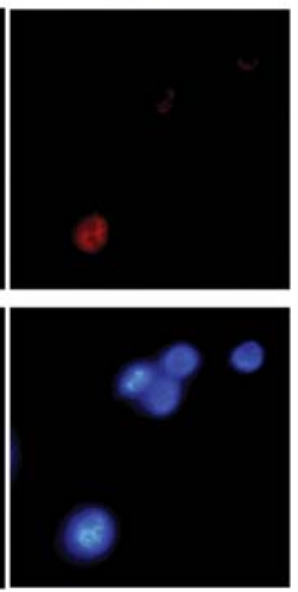

Figure 5. (A) Western blot analysis: $\beta$-catenin is translocated significantly in the nucleus in the CD44 overexpression cell line compared to vector. CD44 knockdown cells showed decreased expression of $\beta$-catenin. Protein p- 84 is internal control. (B) Confocal immunofluorescence images showed increased signal of $\beta$-catenin in CD44 overexpressed cells and decreased signal in CD44 knockdown cells (Red, Alexa Fluor 594; Blue, DAPI).

respect, given its frequent alteration in human cancer, activation of the EGFR/AKT pathway with downregulation of E-cadherin expression and induction of EMT may be particularly important. Loss of the E-cadherin- $\beta$-catenin complex is a significant step in the progression of many epithelial malignancies (34).

The main oncoprotein in colorectal cancer is the Wnt pathway effector $\beta$-catenin, which is overexpressed due to mutations in the APC tumor suppressor in most cases. EMT of the tumor cells is associated with nuclear accumulation of the transcriptional activator $\beta$-catenin. Transcriptional repression of E-cadherin and the associated morphologic changes in cells occur during EMT in embryonic development and in tumor cell invasion. Several transcriptional repressors, including CD44, are implicated in such repression by interacting with 


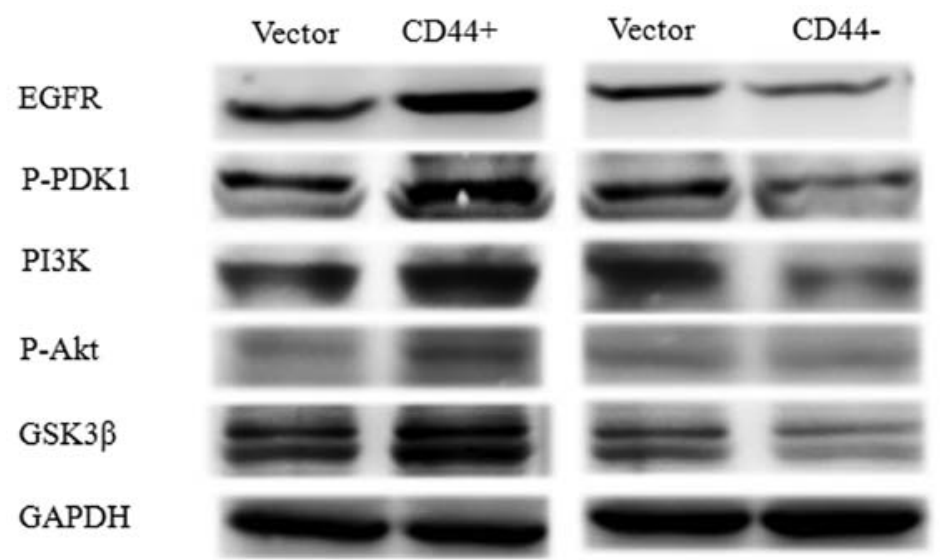

Figure 6. EGFR, phosphorylated PDK1, PI3K, phosphorylated Akt and GSK3 $\beta$ expression were increased in CD44 overexpressed cells and decreased in CD44 knockdown cells, as shown by western blotting.

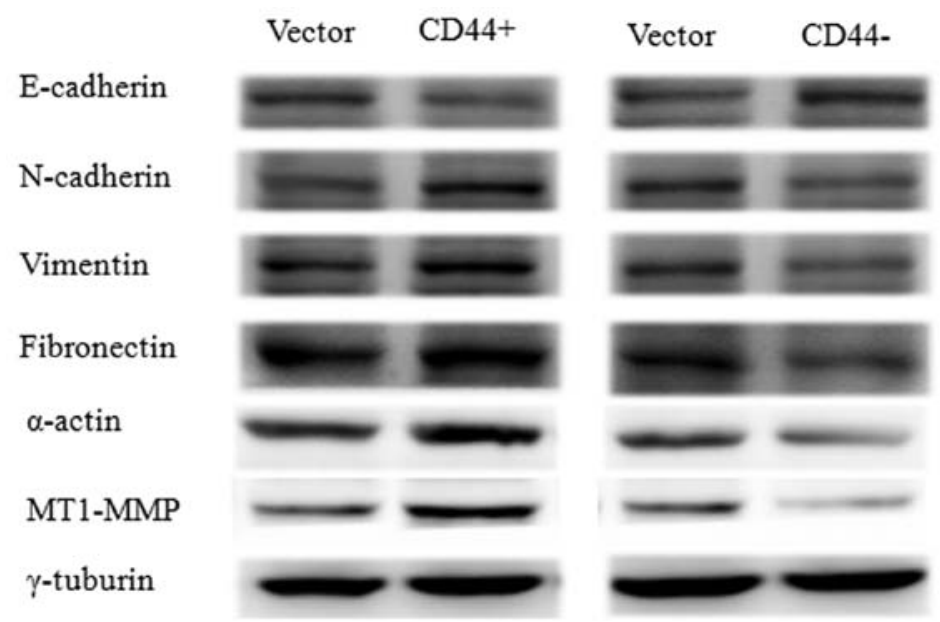

Figure 7. Western blot analysis showed decreased expression of E-cadherin and increased expression of N-cadherin, vimentin, fibronectin, $\alpha$-actin, and MT1-MMP as EMT markers in CD44 overexpressed cells. $\gamma$-tubulin was used as a loading control.

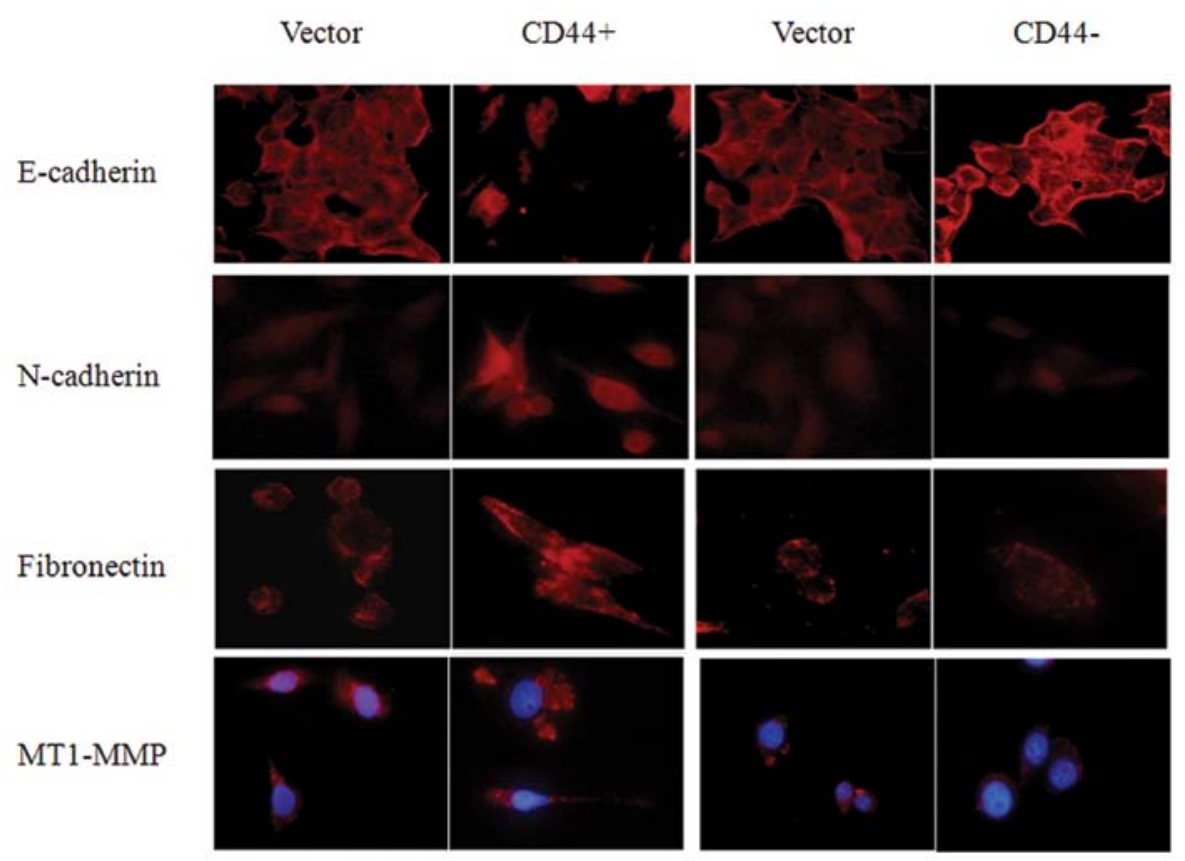

Figure 8. Confocal immunofluorescence images of SW480 cells showed decreased intensity of E-cadherin and increased intensities of N-cadherin, fibronectin and MT1-MMP expression in CD44 overexpressed cells. 
E-cadherin. $\beta$-catenin has a dual role in EMT; it enhances cellcell adhesion when bound to cadherin complexes in adherens junctions and also functions as a transcriptional coactivator upon entry into the nucleus (35). Nuclear import of $\beta$-catenin is another important player in EMT $(36,37)$. Nuclear $\beta$-catenin induces a gene expression pattern favoring tumor invasion and proceeds with transition to the mesenchymal phenotype of epithelial tumor cells (38).

Cells that had undergone EMT exhibited CD44 high expression, suggesting that the EMT may confer malignant properties on tumor cells (39). Upregulation of CD44 and downregulation of CD44 seem to be involved in the EMT process and the acquisition of invasive and metastatic potential (40-43). In this study, treatment with shRNA-CD44 induced CD44 shedding from the cell surface and significantly decreased cell migration and invasion in SW480 cells. This is assumed to be CD44 repression in colorectal cancer cells induced the reconstitution of an epithelial phenotype and reduced the migratory and invasive properties of cancer cells in SW480 cells.

Furthermore, CD44 expression is regulated by the $\beta$-catenin/Tcf-4 signaling pathway, especially in the colorectal cancer precursor lesions, suggesting a role for CD44 in intestinal tumorigenesis. Consequently, nuclear $\beta$-catenin and upregulation of CD44 may be a potential mechanism for colon cancer metastasis $(44,45)$. The requirement of CD44 for EGFR/Akt induced EMT was verified in several reports (46-48). We showed that overexpression of CD44 in SW480 colon cancer cells strongly related to downregulation of E-cadherin, upregulation of $\mathrm{N}$-cadherin and $\alpha$-actin, and vimentin, fibronectin, MT1-MMP, suggesting that CD44 function was a prerequisite for EGFR/Akt -induced responses associated with EMT.

In conclusion, CD44 in SW480 colon cancer cells strongly induced EMT which occurred due to the downregulation of E-cadherin, upregulation of $\mathrm{N}$-cadherin, $\alpha$-actin, vimentin, fibronectin, and MT1-MMT. CD44 also led to EGFR/ Akt-induced signaling associated with EMT. CD44 is a potent EMT inducer and may be an important mediator for invasion and/or metastasis of colon cancer.

\section{Acknowledgements}

This work was supported by a grant from the Research Institute of Medical Sciences, Chonnam National University, 2011-CURIMS-DR007 and a Research Grant 0720570 from the National Cancer Center, South Korea.

\section{References}

1. De Wever O, Pauwels P, De Craene B, Sabbah M, Emami S Redeuilh G, Gespach C, Bracke M and Berx G: Molecular and pathological signatures of epithelial-mesenchymal transitions at the cancer invasion front. Histochem Cell Biol 130: 481-494, 2008.

2. Thiery JP: Epithelial-mesenchymal transitions in tumour progression. Nat Rev Cancer 2: 442-454, 2002.

3. Lionel L and Alfonso B: Epithelial-mesenchymal transition in development and cancer: role of phosphatidylinositol 3' kinase/ AKT pathways. Oncogene 24: 7443-7454, 2005.

4. Huber MA, Kraut N and Beug H: Molecular requirements for epithelial-mesenchymal transition during tumor progression. Curr Opin Cell Biol 17: 548-558, 2005.
5. Hajra KM and Fearon ER: Cadherin and catenin alterations in human cancer. Genes Chromosomes Cancer 34: 255-268, 2002.

6. Brabletz T, Hlubek F, Spaderna S, Schmalhofer O, Hiendlmeyer E, Jung A and Kirchner T: Invasion and metastasis in colorectal cancer: epithelial-mesenchymal transition, mesenchymal-epithelial transition, stem cells and $\beta$-catenin. Cells Tissues Organs 179: 56-65, 2005.

7. Thiery JP and Sleeman JP: Complex networks orchestrate epithelial-mesenchymal transitions. Nat Rev Mol Cell Biol 7: 131-142, 2006.

8. Gruenert S, Jechlinger M and Beug H: Diverse cellular and molecular mechanisms contribute to epithelial plasticity and metastasis. Nat Rev Mol Cell Biol 4: 657-665, 2003.

9. Kalluri R and Neilson EG: Epithelial-mesenchymal transition and its implications for fibrosis. J Clin Invest 112: 1776-1784, 2003.

10. Rodgers, LS, Lalani S, Hardy KM, Xiang X, Broka D, Antin PB and Camenisch TD: Depolymerized hyaluronan induces vascular endothelial growth factor, a negative regulator of developmental epithelial-to-mesenchymal transformation. Circ Res 99: 583-589, 2006.

11. Ponta H, Sherman L and Herrlich PA: CD44: from adhesion molecules to signalling regulators. Nat Rev Mol Cell Biol 4: 33-45, 2003.

12. Nagano $\mathrm{O}$ and Saya $\mathrm{H}$ : Mechanism and biological significance of CD44 cleavage. Cancer Sci 95: 930935, 2004.

13. Haynes BF, Hale LP, Patton KL, Martin ME and McCallum RM: Measurement of an adhesion molecule as an indicator of inflammatory disease activity. Up-regulation of the receptor for hyaluronate (CD44) in rheumatoid arthritis. Arthritis Rheum 34: 1434-1443, 1991.

14. Kuppner MC, Liversidge J, McKillop-Smith S, Lumsden L and Forrester JV: Adhesion molecule expression in acute and fibrotic sympathetic ophthalmia. Curr Eye Res 12: 923-934, 1993.

15. Florquin S, Nunziata R, Claessen N, van den Berg FM, Pals ST and Weening JJ: CD44 expression in IgA nephropathy. Am J Kidney Dis 39: 407-414, 2002.

16. Svee K, White J, Vaillant P, Jessurun J, Roongta U, Krumwiede M, Johnson D and Henke C: Acute lung injury fibroblast migration and invasion of a fibrin matrix is mediated by CD44. J Clin Invest 98: 1713-1727, 1996.

17. Teder P, Vandivier RW, Jiang D, Liang J, Cohn L, Pure E, Henson PM and Noble PW: Resolution of lung inflammation by CD44. Science 296: 155-158, 2002.

18. Rouschop KM, Sewnath ME, Claessen N, Roelofs JJ, Hoedemaeker I, van der Neut R, Aten J, Pals ST, Weening JJ and Florquin S: CD44 deficiency increases tubular damage but reduces renal fibrosis in obstructive nephropathy. J Am Soc Nephrol 15: 674-686, 2004.

19. Noble PW and Jiang D: Matrix regulation of lung injury, inflammation, and repair: the role of innate immunity. Proc Am Thorac Soc 3: 401-404, 2006.

20. Holgate ST: Asthma: a dynamic disease of inflammation and repair. Ciba Found Symp 206: 106-110, 1997.

21. Jain M, He Q, Lee WS, Kashiki S, Foster LC, Tsai JC, Lee ME and Haber E: Role of CD44 in the reaction of vascular smooth muscle cells to arterial wall injury. J Clin Invest 98: 877, 1996.

22. Mikecz K, Brennan FR, Kim JH and Glant TT: Anti-CD44 treatment abrogates tissue oedema and leukocyte infiltration in murine arthritis. Nat Med 1: 558-563, 1995.

23. Pure $\mathrm{E}$ and Cuff CA: A crucial role for CD44 in inflammation. Trends Mol Med 7: 213-221, 2001.

24. Grandis JR and Sok JC: Signaling through the epidermal growth factor receptor during the development of malignancy. Pharmacol Ther 102: 37-46, 2004.

25. Dancey JE: Predictive factors for epidermal growth factor receptor inhibitors - the bull's eye hits the arrow. Cancer Cell 5: 411-415, 2004.

26. Nagane M, Lin H, Cavenee WK and Huang HJ: Aberrant receptor signaling in human malignant gliomas: mechanisms and therapeutic implications. Cancer Lett 162 (Suppl): S17-21, 2001.

27. Fuster LM and Sandler AB: Select clinical trials of erlotinib (OSI-774) in non-small-cell lung cancer with emphasis on phase III outcomes. Clin Lung Cancer (Suppl) 1: S24-29, 2004.

28. Rosivatz E, Becker I, Specht K, Fricke E, Luber B, Busch R, Höfler $\mathrm{H}$ and Becker KF: Differential expression of the epithelial-mesenchymal transition regulators Snail, SIP1, and Twist in gastric cancer. Am J Pathol 61: 1881-1891, 2002. 
29. Elloul S, Elstrand MB, Nesland JM, Tropé CG, Kvalheim G, Goldberg I, Reich R and Davidson B: Snail, Slug, and Smad-interacting protein 1 as novel parameters of disease aggressiveness in metastatic ovarian and breast carcinoma. Cancer 103: $1631-1643,2005$

30. Kwok WK, Ling MT, Lee TW, et al: Up-regulation of TWIST in prostate cancer and its implication as a therapeutic target. Cancer Res 65: 5153-5162, 2005.

31. Uchikado $Y$, Natsugoe $S$, Okumura $H$, Setoyama $T$, Matsumoto M, Ishigami S and Aikou T: Slug epression in the E-cadherin preserved tumors is related to prognosis in patients with esophageal squamous cell carcinoma. Clin Cancer Res 11: 1174-1180, 2005

32. Woodhouse EC, Chuaqui RF and Liotta LA: General mechanisms of metastasis. Cancer 80: 1529-1537, 1997.

33. Kirchner T and Brabletz T: Patterning and nuclear beta-catenin expression in the colonic adenoma-carcinoma sequence: Analogies with embryonic gastrulation. Am J Pathol 157: $1113-1121,2000$

34. Lim SC and Lee MS: Significance of E-cadherin/beta-catenin complex and cyclin D1 in breast cancer. Oncol Rep 9: 915-928, 2002 .

35. van Es JH, Barker $\mathrm{N}$ and Clevers H: You Wnt some, you lose some: oncogenes in the Wnt signaling pathway. Curr Opin Genet Dev 13: 28-33, 2003.

36. Brabletz T, Jung A, Spaderna S, Hlubek F and Kirchner T: Migrating cancer stem cells - an integrated concept of malignant tumor progression. Nat Rev Cancer 5: 744-749, 2005.

37. Yang L, Lin C and Liu ZR: P68 RNA helicase mediates PDGFinduced epithelial mesenchymal transition by displacing Axin from beta-catenin. Cell 127: 139-155, 2006.

38. Schmalhofer O, Brabletz S and Brabletz T: E-cadherin, betacatenin, and ZEB1 in malignant progression of cancer. Cancer Metastasis Rev 28: 151-166, 2009.

39. Mani SA, Guo W, Liao MJ, Eaton EN, Ayyanan A, Zhou AY, et al: The epithelial-messenchymal transition generates cells with properties of stem cells. Cell 133: 704-715, 2008
40. Hill A, McFarlane S, Mulligan K, Gillespie H, Draffin JE, Trimble A, et al: Cortactin underpins CD44-promoted invasion and adhesion of breast cancer cells to bone marrow endothelial cells. Oncogene 25: 6079-6091, 2006.

41. Schabath H, Runz S, Joumaa S and Altevogt P: CD24 affects CXCR4 function in pre-B lymphocytes and breast carcinoma cells. J Cell Sci 119: 314-325, 2006.

42. Müller A, Homey B, Soto H, Ge N, Catron D, Buchanan ME, et al: Involvement of chemokine receptors in breast cancer metastasis. Nature 410: 50-56, 2001.

43. Hamada J, Sawamura Y and Van Meir EG: CD44 expression and growth factors. Front Biosci 3: d657-d664, 1998.

44. Wielenga VJ, Smits R, Korinek V, Smit L, Kielman M, Fodde R, Clevers $\mathrm{H}$ and Pals ST: Expression of CD44 in Apc and Tcf mutant mice implies regulation by the WNT pathway. Am J Pathol 154: 515-523, 1999.

45. Zeilstra J, Joosten SP, Dokter M, Verwiel E, Spaargaren M and Pals ST: Deletion of the WNT target and cancer stem cell marker $\mathrm{CD} 44$ in Apc(Min/+) mice attenuates intestinal tumorigenesis. Cancer Res 68: 3655-3661, 2008.

46. Deckers M, van Dinther M, Buijs J, Que I, Ladwik C, van der Pluijm G and ten Dijke P: The tumor suppressor SMAD4 is required for transforming grow th factor beta-induced epithelial to mesenchymal transition and bone metastasis of breast cancer cells. Cancer Res 66: 2202-2209, 2006.

47. Piek E, Moustakas A, Kurisaki A, Heldin CH and ten Dijke P: TGF- $\beta$ type I receptor/ALK-5 and SMAD proteins mediate epithelial to mesenchymal transdifferentiation in NMuMG breast epithelial cells. J Cell Sci 112: 4557-4568, 1999.

48. Valcourt U, Kowanetz M, Niimi H, Heldin CH and Moustakas A: TGF-beta and the SMAD signaling pathway support transcriptomic reprogramming during epithelial-mesenchymal cell transition. Mol Biol Cell 16: 1987-2002, 2005. 